\title{
圈 \\ The Readability of Sustainability Reporting in New Zealand over time
}

\author{
Azadeh (Azi) Nilipour ${ }^{1}$, Tracy-Anne De Silva ${ }^{2}$ and Xuedong $\mathbf{L i}^{3}$
}

\begin{abstract}
This paper examines the readability of sustainability reporting in the annual reports, and stand-alone reports of New Zealand listed companies over a ten-year period. Sustainability reporting was manually extracted from 264 reports, and readability software was used to identify the readability scores using five readability indices. Additionally, the effects of reporting quantity, environmental sensitivity, and global listing on the readability of sustainability reporting were examined.
\end{abstract}

The results show that over the ten-year period readability has improved by only 6.5 per cent, despite a substantial increase in the number of companies reporting sustainability information, and an increase in the quantity of sustainability reporting from almost a third of the companies. This research also finds that there is a statistically significant negative correlation between the average readability score and reporting quantity; meaning longer sustainability reports have lower readability scores (i.e. they are more readable). The findings indicate that environmentally sensitive companies published more readable sustainability information in comparison to companies from non-environmentally sensitive industries. However, in terms of readability, there is no difference between the reports published by companies listed only on the New Zealand Stock Exchange (NZX) and the reports published by companies listed on multiple stock exchanges.

This research is the first readability study examining sustainability reporting in New Zealand. It provides companies, users of sustainability information and regulators with knowledge of the readability of voluntary sustainability reporting, showing that little change has occurred over time. It suggests a strong possibility of obfuscation and thus, a risk that sustainability reporting is sending the wrong signal to stakeholders.

JEL classification: M41, Q56

Keywords: Readability, Sustainability Reporting, Obfuscation, Quantity, Environmental Sensitivity, New Zealand Stock Exchange (NZX), Global Listing

\footnotetext{
${ }^{1}$ Corresponding author. Lincoln University Christchurch, New Zealand. Email : Azadeh.Nilipour@lincoln.ac.nz

${ }^{2}$ Lincoln University Christchurch, New Zealand.

${ }^{3}$ Lincoln University Christchurch, New Zealand.
} 
Nilipour, De Silva \& Li | The Readability of Sustainability Reporting in New Zealand over time

\section{INTRODUCTION}

In fulfilling their obligation, under the concept of a social contract, to act in a socially responsible manner, organisations have a number of tools available, including communication in the form of the release of information via reports to external stakeholders (Gray, Owen, \& Adams, 1996; Huang \& Kung, 2010; Tregidga \& Milne, 2006). During the early 2000s, as a result of increasing scrutiny over sustainability performance, various stakeholders have demanded reports that disclose information on the economic, environmental and social performance (i.e. sustainability performance) of an organisation (Brockett \& Rezaee, 2012). This has led to an increase in sustainability reporting (KPMG, 2017; Nazari, Hrazdil, \& Mahmoudian, 2017; Smeuninx, De Clerck, \& Aerts, 2016), a concept that has been defined by Rowe (2013, p. 223) as:

a means to measure organisational performance towards the goal of sustainability, thereby providing useful information for decision-making and discharging accountability to stakeholders through reporting.

Sustainability reporting remains voluntary in most countries. However, France and South Africa have mandatory integrated reporting, the United Kingdom and Singapore passed legislation that requires large firms or publicly-listed companies to report on their social and environmental performance, and several laws and regulations in Canada and the United States mandated sustainability reporting (Brockett \& Rezaee, 2012). Whether reporting is voluntary or mandatory, there is still a large variation in the sustainability information reported by companies (KPMG, 2017; McCrary, 2002; Nazari et al., 2017; Owen, 2006).

These reporting inconsistencies have created difficulties over the years in determining the completeness of the information (Gray, 1990; Wiseman, 1982) and have led to a lack of comparability and credibility (Beets \& Souther, 1999). Sustainability reporting varies in quality due to the plethora of reasons for companies engaging in sustainability reporting, ranging from genuine to a self-congratulatory-public-relations exercise (e.g. Hooghiemstra, 2000; Scott, 2001; Wang, Hsieh \& Sarkis, 2018; Smeuninx et al., 2016). Reporting is inherently subjective (Abu Bakar \& Ameer, 2011) and "information may be perceived, presented and interpreted by different people in different ways" (Alexander \& Jermakowicz, 2006, p. 134), however, reporting enables an organisation to be accountable, democratic and transparent to its stakeholders (Yongvanich \& Guthrie, 2006), empowering them and stimulating business change (Larrinaga-González,

Carrasco-Fenech, Caro-González, Correa-Ruiz, \& Páez-Sandubete, 2001). The reporting of sustainability information should, therefore, form part of the organisation-stakeholder dialogue (Gray, Kouhy, \& Lavers, 1995), and is a key step towards meeting society's demands for more corporate social responsibility (CSR) (Ballou, Heitger, \& Landes, 2006; Yongvanich \& Guthrie, 2006). Drawing a corollary with the purpose of financial reporting, sustainability reporting should "... give an understanding, which is not misleading ..." of the social and environmental consequences of an organisation's actions and activities (adapted from Alexander \& Jermakowicz, 2006, p. 132). Thus, a comprehensive sustainability report should not only disclose both positive and negative aspects of performance but also satisfy the needs of all stakeholders (Brockett \& Rezaee, 2012).

According to a recent report published by the Sustainable Business Council (2019), New Zealanders are seeking more information about the sustainability of businesses. Seventy-one per cent of New Zealanders actively search for information about sustainability before purchasing any 
products, and 47 per cent of New Zealanders incorporate sustainability-related information in their decision making (Sustainable Business Council, 2019). Regulators in New Zealand are also calling for change, with the NZX Corporate Governance Code published in 2017 requiring all listed companies on the NZX to provide environmental, social and governance (ESG) information (NZX, 2017). However, the current voluntary nature of sustainability reporting, and the lack of sustainability reporting and assurance requirements in New Zealand, gives companies flexibility in what they report which could result in them obfuscating their sustainability information to influence users' decision-making process (Wang et al., 2018).

Freedman and Stagliano (1992, p. 115) stated that "the critical attribute is the meaning of the words". This sentiment has also been noted by other researchers, including Ballou et al. (2012) who call for research that focusses on the content of the reporting. However, numerous prior studies have failed to consider reporting content or quality and have instead focused on reporting quantity. Reporting quality refers to "completeness, accuracy and reliability" (Singhvi \& Desai, 1971, p. 131), however, as with many concepts, reporting quality "is neither a readily measurable nor a generally agreed-upon characteristic" (Bernstein and Siegel, 1982, as cited in Imhoff, 1992, pp. 98-99). Wiseman (1982) was one of the first studies to examine reporting quality, with other researchers following and expanding the measure of quality (see Nazari et al., 2017 for a brief discussion). However, researchers examining reporting quality have paid little attention to readability (Smeuninx et al., 2016). Reporting quality, and thus, readability can have a significant influence on the quality of the decisions made by stakeholders, and thus should be considered by companies reporting information to the public (Brink, Haines, Owen, Smith, \& Whitaker, 1997; Lehavy, Li, \& Merkley, 2011; Li, 2008; Singhvi \& Desai, 1971; Wang et al., 2018).

Readability refers to the ease of reading (Harris \& Hodges, 1995; Smeuninx et al., 2016). It is a concept that has been examined by a number of researchers with respect to financial reporting, but only a few recent studies (e.g. Abu Bakar \& Ameer, 2011; Nazari et al., 2017; Smeuninx et al., 2016; Wang et al., 2018) have examined the readability of sustainability reporting. Prior studies examining the readability of sustainability reporting have generally found the readability to be poor (Smeuninx et al., 2016; Richards, 2011), with some studies specifically examining the "obfuscation hypothesis" (Courtis, 1998) and finding support that managers make bad news more difficult to read (Nazari et al., 2017; Smeuninx et al., 2016). Further, studies have found a relationship between CSR performance and readability (e.g. Nazari et al., 2017). While these studies provide some insights into the readability of sustainability reporting, little is known about the changes over time and how certain determinants affect readability.

Given the voluntary nature of sustainability reporting in New Zealand, the increasing demands from the New Zealand public for sustainability information, and the importance of readability to the quality of sustainability reporting, the purpose of this research is to examine the readability of sustainability reporting over time in New Zealand. This is achieved through an examination of the annual reports and stand-alone reports of companies listed on the NZX. In particular, this research examines whether readability has changed over time based on specific characteristics, including sustainability reporting quantity, environmental sensitivity, and whether the company is listed globally.

The remainder of this paper is structured as follows. The next section reviews prior literature and theories related to sustainability reporting, as well as readability. This is followed by an outline of 
Nilipour, De Silva \& Li | The Readability of Sustainability Reporting in New Zealand over time

the methods used in this research. The results are then presented and discussed. The final section draws conclusions, outlines the limitations of the research, and identifies areas for future research.

\section{LITERATURE REVIEW AND THEORETICAL FOUNDATION}

Effective sustainability reporting can be achieved via the provision of sufficient, high-quality information to facilitate the decision-making process of stakeholders. Communication plays an instrumental role in fulfilling social contracts and the legitimation process (Cormier, Gordon and Magnan, 2004; Solomon \& Lewis, 2002). Both reputation risk management and legitimacy management rely heavily on communication (Bebbington, Larrinaga, \& Moneva, 2008; Cormier et al., 2004; Deegan, 2002; O'Dwyer, 2002; Suchman, 1995), and a failure to communicate to stakeholders how the organisation's actions and activities impact on the natural environment and society can lead to a loss of the social licence to operate, image and reputation, and legitimacy. Thus, communication is vital to ensure organisations demonstrate how and/or why their actions and activities do, or do not, align with society's changing perceptions (i.e. social contracts) (Newson \& Deegan, 2002).

The release of information is often viewed as a response to the social pressure applied via governments (Guthrie \& Parker, 1990), and seen as an effective way to manage public perceptions (Bebbington et al., 2008). Further, the production and publication of information helps to demonstrate accountability (Perks, 1993) and provides organisations with a mechanism to show stakeholders they have "nothing to hide, and therefore ... nothing to fear" (Browne, 2002, p. 34), as without external reporting on sustainability impacts "society is unable to assess the adequacy of measures undertaken to protect the environment [and society]" (Brennan, 1993, p. 61).

The reporting of all information (i.e. warts and all reporting) is likely to "detract attention from more serious issues" (Hammond \& Miles, 2004, p. 75). Prior behavioural studies provide partial support "for the idea that there can be such a thing as too much information" (see Buzby, 1974, p. 44) leading to the incorrect interpretation of the message. Excessive reporting overwhelms readers with irrelevancies and minutiae. Information overload can also be achieved by decreasing the readability of narrative information, which can also obfuscate negative information (Wang et al. 2018).

The resultant inefficient incoherence of reporting everything to everybody must be compared to the problems of failing to report sufficient relevant detail (Buzby, 1974). It is important to tradeoff detail and synopsis, achieving a balance. Reporting is frequently used "to signal expectations and intentions" (Frias-Aceituno et al., 2012; Godfrey et al., 2000, p. 302), demonstrate sustainability practice (Legendre \& Coderre, 2012), and enhance reputation (Melo \& GarridoMorgado, 2012). On the basis of signalling theory, reporting is often interpreted as good news by markets, while a failure to report is often interpreted as bad news (Christensen \& Demski, 2004; Riahi-Belkaoui, 2004; Toms, 2002). Choosing to disclose more good news to improve reputation has been a finding of prior studies (e.g. Habbitts \& Gilbert, 2007; Mermod \& Idowu, 2013), however, management also have "reputational incentives" to disclose bad news (Skinner, 1994, p. 40 ), as the reporting of bad news is often "selective, or reflects information that is already in the public domain, as opposed to providing honest coverage" (Hammond \& Miles, 2004, p. 75). In an attempt to further legitimise their sustainability activities, companies may choose to obfuscate inferior sustainability information through manipulating the readability (Abu Bakar \& Ameer, 2011; Merkl-Davies \& Brennan; Wang et al. 2018) and using language to mould the narrative to the company's advantage (Boiral, 2003; Parsons and McKenna, 2005). Contrastingly, Rutherford 
(2003) suggested that firms with good performance will report information with more clarity to signal their superiority.

\subsection{Readability}

The concept of readability has been defined differently by scholars. Some definitions strongly focus on 'reading ease'. For example, readability is defined as "whether a text can be read quickly and easily" (Schroeder \& Gibson, 1990) or "the text-internal characteristic of what makes some texts easier to read than others" (DuBay, 2004). Other definitions place a focus on 'understandability' and 'comprehensibility' as two key concepts for readability (Klare, 1963; McLaughlin, 1969), while some studies distinguish readability from understandability (Smith \& Taffler, 1992). Smith \& Taffler (1992) believed readability is solely related to text-internal characteristics that determine text difficulty, while understandability is about the interaction between the text and its reader and could be affected by prior knowledge.

Given the debate around the concept of readability, similar to Smeuninx et al. (2016), this research assumes that a text is more readable when a text's features make it easier for the reader to extract desired information. This research considers five common readability indices: the Flesch-Kincaid Grade Level, Gunning Fog, Coleman Liau, SMOG, and Automated Readability, as according to Courtis (1998), readability formulae are a method to quantify whether the target audience is able to read and understand the written massage.

\subsection{Determinants of Report Readability}

Some prior studies examining readability, primarily of financial reporting, have grouped the determinants of readability into "firm-specific factors and factors related to the characteristics of the report preparer" (Boritz, Hayes, \& Timoshenko, 2016, p. 147). Other studies have focussed primarily on firm performance (e.g. Li, 2008; Lo, Ramos, \& Rogo, 2017). This research looks specifically at three determinants of readability: sustainability reporting quantity, environmental sensitivity, and whether the company listed globally.

\subsubsection{Sustainability reporting quantity}

Reporting quantity has been examined in numerous prior studies on sustainability reporting and has also been included in some readability studies, often as a measure of complexity (see Nazari et al., 2017 for a brief discussion). Boritz et al. (2016), following Loughran and McDonald (2014) who studied the readability of $10-\mathrm{K}$ reports, hypothesised that report length (i.e. file size) would have a negative relationship with the readability of SOX 404 reports. However, they found that for SOX 404 reports, "longer reports are more readable than shorter reports" (p. 162). This suggests that the impact of report length on readability differs between report types. Thus, this research focuses only on the sustainability information which is included in annual reports and stand-alone reports.

\subsubsection{Environmental sensitivity}

Sustainability reporting is believed to be higher in some industries than others due to government pressure, consumer relationships and consumer responsiveness (KPMG, 2017). Companies operating in environmentally sensitive, or high profile, industries have "consumer visibility, a high level of political risk, and concentrated intense competition" (Roberts, 1992, p. 605). As their economic activities modify or are likely to modify, the natural environment, they "are assumed to have a greater incentive for projecting a positive social image" (Patten, 1991, p. 303). Thus, it is 
expected that companies operating in environmentally sensitive industries would have an incentive to report sustainability information that is more readable than that of companies that operate in non-environmentally sensitive industries. Prior studies identify that the environmental sensitivity of an industry or sector affects sustainability reporting quantity (Cormier \& Gordon, 2001), and Boritz et al. (2016) found an association between industry and readability in their study of SOX 404 reports. However, Smeuninx et al. (2016) found little industry impact in their readability study of sustainability reports.

\subsubsection{Global listing}

The mandating of sustainability reporting and higher sustainability reporting rates in some countries (KPMG, 2017) indicate that there are countries other than New Zealand who are better performers in terms of sustainability reporting. Thus, it can be expected that the readability of sustainability reporting in New Zealand would be enhanced by the influence of other countries. The global culture adopted by cross-listed companies was recognised by Kumar (2014) in their readability study of financial reports. Further, Smeuninx et al. (2016) discussed the impact of the region on readability. They found that the region has the most significant effect on readability in their study. While they focused on regions with respect to language variety, their findings suggest that the listing market influences readability. Thus, this research distinguishes between those companies that are listed in New Zealand from those that are also listed on the stock exchanges of other countries.

The discussion above leads to the following research questions:

1. What is the readability level of sustainability reporting?

2. What is the relationship between the quantity and the readability of sustainability reporting?

3. What is the relationship between environmental sensitivity and the readability of sustainability reporting?

4. What is the relationship between being listed globally, and not just in New Zealand, and the readability of sustainability reporting?

\section{METHOD}

\subsection{Sample Selection}

The research sample consists of the NZX companies reporting sustainability information in their annual reports or stand-alone sustainability reports. Sustainability information was identified in annual reports through a keyword search of words related to sustainability, social, and environmental. The keyword search was undertaken on the 2016 annual reports for each company, being the latest financial year available for all companies at the time the research commenced. The keyword search was also undertaken on earlier reports; however, it was assumed that if a company had not reported sustainability information for two consecutive years, they had not reported sustainability information earlier, and their annual reports or stand-alone reports were no longer searched. The search resulted in 37 companies reporting sustainability information during the tenyear period 2007-2016, equating to 264 research observations. The sustainability information identified in the annual reports and the stand-alone reports were manually extracted and saved in M.S. Word for ease of use in the readability software. 


\subsection{Factor Measurements}

\subsubsection{A measure of sustainability reporting quantity}

According to literature around written communications and particularly sustainability reporting research, page proportions, words, and sentences dedicated to the information of interest are the preferred units of measurement and analysis (Gray et al., 1995). All these three units have been criticised over the years. The use of words is considered inappropriate due to words being an ambiguous measure, with researchers needing to decide which word is disclosure and which is not (Hackston and Milne, 1996), adding unnecessary unreliability (Milne and Adler, 1999). Furthermore, words need a sentence or sentences to create a context (Milne and Adler, 1999) and provide a way to infer meaning (Gray et al., 1995). Sentences are often criticised because of their inability to recognise differences in typography between reports (Hackston and Milne, 1996, Unerman, 2000). Further, using sentences as the unit of measurement does not allow the writing abilities of different report preparers to be recognised, and ignores the use of graphics, which can be powerful and effective methods of communication (Unerman, 2000). The use of page proportions helps to reflect the amount of space and consequently indicates the importance of a disclosure (Gray et al., 1995) but can result in some of the richness of the data being lost. Page proportions have also been criticised as being a meaningless measure that adds unnecessary unreliability (Milne and Adler, 1999).

Considering these criticisms, this research identified the quantity of sustainability information by looking at the number of pages or part pages dedicated to sustainability-related topics. This method was used in the New Zealand context by Morunga and Bradbury (2012) to analyse the impact of international financial reporting standards on the annual reports of NZX companies.

This research chose to use annual reports as the main source of sustainability reporting and also considered stand-alone reports. The annual report - traditionally one of the main communication media for companies (Adams \& Harte, 1998; Neu et al., 1998) - is consistently (and mandatorily) issued as part of a company's reporting cycle to shareholders and other stakeholders. Despite an increase in the number of stand-alone sustainability reports being issued, many companies still include sustainability reporting in their annual reports and thus, these two sources were considered suitable for examining the readability of sustainability reporting in New Zealand.

The annual reports and stand-alone reports of each sample company were accessed from the sample company's website. The sustainability information identified in the annual reports through the keyword search was categorised, using pages and part pages as the unit of measurement for quantity, as "low", "medium" or "high". Companies with low reporting quantity - identified as companies reporting sustainability information that was included in general sections of the annual report and was less than one page in total length - were given a score of one. Companies with medium reporting quantity - identified as companies reporting sustainability information that was in a separate section or sub-section related to sustainability in the annual report and was one page or more in length - were given a score of two. Finally, a score of three was given to companies with high reporting quantity which was considered to be those companies that prepare a standalone sustainability report. 
Nilipour, De Silva \& Li | The Readability of Sustainability Reporting in New Zealand over time

\subsubsection{A measure of environmental sensitivity}

Given the small sample size of NZX companies publishing sustainability information, classifying companies based on the industry sector would not provide meaningful results since very few companies fall into each industry sector. Therefore, the Global Industry Classification Standard (GICS) was used to divide the sample companies into two main categories: environmentally sensitive, and non-environmentally sensitive industries. All ten sectors in the GICS classification were used to match the relevant information published on the NZX website. Companies labelled as Consumer Discretionary, Energy, Materials, Industrials and Utilities were classified as environmentally sensitive, while companies classified as Consumer Staples, Health Care, Financials, Information Technology and Telecommunication Services were considered as nonenvironmentally sensitive.

\subsubsection{A measure of global listing}

To distinguish those companies who listed domestically from those who are listed globally - as explained in section 0 above - an internet search was conducted to recognise whether companies are listed only on the NZX or listed on multiple stock markets (global listing).

\subsubsection{Measures of information readability}

This research applied a textual analysis technique - using the number of syllables, words and sentences - to the sustainability information extracted from annual reports and stand-alone reports to measure the readability of such corporate communications.

To increase the efficiency and accuracy, this research relied on an online readability software tool - ReadablePro - to compute the following five readability indices: Flesch-Kincaid Grade Level, Gunning Fog, Coleman-Liau, SMOG, and Automated Readability. As suggested by prior studies, the average of all readability indices was also calculated (Nazari et al., 2017). This online tool is a text analysis software program designed to calculate all the common indices from a Microsoft Word or a PDF document based on factors like sentence length, syllable count and the percentage of multi-syllable (complex) words.

Flesch-Kincaid Grade Level (FGL) has been the most common and the easiest index used by researchers. This index quantifies the years of education that the text requires of the reader. In other words, this score indicates the minimum level of education required in order to understand the subject material. Text with a low FGL score is more readable, which means readers with lower comprehension skills can read it more easily (Kincaid, Fishburne, Rogers \& Chissom, 1975; Smeuninx, 2016). Gunning Fog is another commonly used score. This index was introduced by Gunning (1952) and calculates the grade level (years of formal education) needed to understand the text. This score is very similar to FGL but places more emphasis on the percentage of complex words (words with three or more syllables) in the text (Li, 2008). In addition to FGL and FOG, which are the most commonly used readability indices in prior studies, this research considered three more measures which have a similar interpretation but use different formulas to compute readability. Coleman Liau (CLI) computes the grade level of a document based on sentence length and word length (letter count); SMOG calculates the years of education an individual needs to understand a piece of writing using the number of complex words in sample sentences; and Automated Readability (A.R.) measures the grade level of a document based on sentence length and character count. 
Overall, a high score for any of the readability indices indicates low readability or high complexity. Table 1 shows the exact formula used to calculate these readability indices.

Table 1 Readability formulas

\begin{tabular}{|l|l|}
\hline \multicolumn{1}{|c|}{ Readability index } & \multicolumn{1}{c|}{ Readability formula } \\
\hline Flesch-Kincaid Grade Level & $(11.8 *$ syllables per word $)+(0.39 *$ Words per sentence) -15.59 \\
\hline Gunning Fog & $0.4 *$ (Words per sentence + percentage of complex words) \\
\hline Coleman Liau & $\begin{array}{l}0.0588 * \text { Average number of letter per } 100 \text { words })-0.296 * \text { (average } \\
\text { number of sentences per } 100 \text { words })-15.8\end{array}$ \\
\hline SMOG & $3+$ Square Root of complex word count (for the selected 30 sentences) \\
\hline Automated Readability & $\begin{array}{l}4.71 *(\text { Number of letter per words) }+0.5 * \text { (Number of Word per } \\
\text { sentence })-21.4\end{array}$ \\
\hline
\end{tabular}

\section{RESULTS AND DISCUSSION}

Once the readability scores were calculated through the online tool for each of the readability indices, various analysis techniques were used to examine the data.

\subsection{Overall Trend}

The research sample includes 264 extracts of sustainability reporting from the annual reports and stand-alone reports issued by 37 companies listed on NZX from $2007-2016$. Table 2 presents the descriptive statistics, including the number of observations in each year, median values and standard deviations of all the readability indices calculated.

Table 2 Descriptive statistics

\begin{tabular}{|c|c|c|c|c|c|c|c|c|c|c|c|c|c|}
\hline \multirow[t]{2}{*}{ Year } & \multirow[t]{2}{*}{ No } & \multicolumn{2}{|c|}{$\begin{array}{l}\text { Flesch- } \\
\text { Kincaid } \\
\text { Grade } \\
\text { Level } \\
\end{array}$} & \multicolumn{2}{|c|}{$\begin{array}{l}\text { Gunning } \\
\text { Fog Index }\end{array}$} & \multicolumn{2}{|c|}{$\begin{array}{l}\text { Coleman- } \\
\text { Liau Index }\end{array}$} & \multicolumn{2}{|c|}{$\begin{array}{l}\text { SMOG } \\
\text { Index }\end{array}$} & \multicolumn{2}{|c|}{$\begin{array}{l}\text { Automated } \\
\text { Readability } \\
\text { Index }\end{array}$} & \multicolumn{2}{|c|}{$\begin{array}{c}\text { Average } \\
\text { Grade } \\
\text { Level }\end{array}$} \\
\hline & & M & SD & M & SD & M & SD & M & SD & M & SD & M & SD \\
\hline 2007 & 20 & 13.00 & 2.33 & 15.70 & 2.97 & 14.50 & 1.55 & 14.80 & 2.27 & 13.40 & 2.79 & 13.80 & 2.31 \\
\hline 2008 & 21 & 13.70 & 2.31 & 15.70 & 2.68 & 14.10 & 1.39 & 15.40 & 2.22 & 14.20 & 3.07 & 14.80 & 2.27 \\
\hline 2009 & 22 & 13.80 & 2.57 & 15.65 & 2.95 & 14.45 & 1.67 & 15.80 & 2.57 & 13.90 & 3.24 & 14.95 & 3.86 \\
\hline 2010 & 25 & 13.50 & 2.26 & 15.30 & 2.67 & 14.40 & 1.36 & 15.50 & 2.12 & 14.10 & 2.82 & 14.50 & 3.52 \\
\hline 2011 & 24 & 12.60 & 2.29 & 14.80 & 2.67 & 14.40 & 1.38 & 14.85 & 2.10 & 13.15 & 2.76 & 13.55 & 3.52 \\
\hline 2012 & 28 & 12.95 & 2.15 & 15.10 & 2.69 & 14.30 & 1.74 & 15.20 & 2.08 & 12.85 & 2.71 & 14.00 & 2.14 \\
\hline 2013 & 27 & 11.90 & 1.95 & 14.20 & 2.44 & 13.95 & 1.45 & 14.10 & 1.92 & 12.25 & 2.52 & 13.20 & 3.27 \\
\hline 2014 & 28 & 13.20 & 2.10 & 15.30 & 2.57 & 13.80 & 1.36 & 15.10 & 2.06 & 13.70 & 2.74 & 14.30 & 3.08 \\
\hline 2015 & 33 & 12.70 & 2.51 & 14.55 & 2.99 & 13.80 & 1.43 & 14.60 & 2.37 & 13.40 & 3.08 & 13.80 & 3.25 \\
\hline 2016 & 36 & 11.80 & 1.92 & 13.80 & 2.45 & 13.70 & 0.97 & 14.50 & 1.92 & 12.10 & 2.51 & 12.90 & 1.84 \\
\hline
\end{tabular}


Although the number of companies publishing sustainability reporting increased significantly by 80 per cent (from 20 in 2007 to 36 in 2016), there has not been much change in the readability scores of the information. The sustainability reporting becomes more readable only by 6.5 per cent. As shown in Figure 1, all the readability indices, despite having different formulas and considering various aspects of a text, present a consistent trend during the research period.

In contrast to a prior study of New Zealand and Australian companies in 2011, the finding of this research does not indicate extremely poor readability scores. Richards (2011) revealed very high readability scores - i.e. an average of 15.05 for Flesch-Kincaid Grade Level - which is similar to the readability score calculated for academic papers, requiring readers to have Honours or Master's degrees. The similar average score computed in this research is 12.89 , which is considered 'difficult' requiring readers to have at least a Bachelor's degree to understand the text. However, comparing readability scores with the 2013 census data highlights that only 20 per cent of the New Zealand population would be able to read, understand and make an informed decision based on sustainability reporting (Statistics New Zealand, 2013). According to Census 2018, this figure improved by only 3 per cent in five years (Statistics New Zealand, 2018).

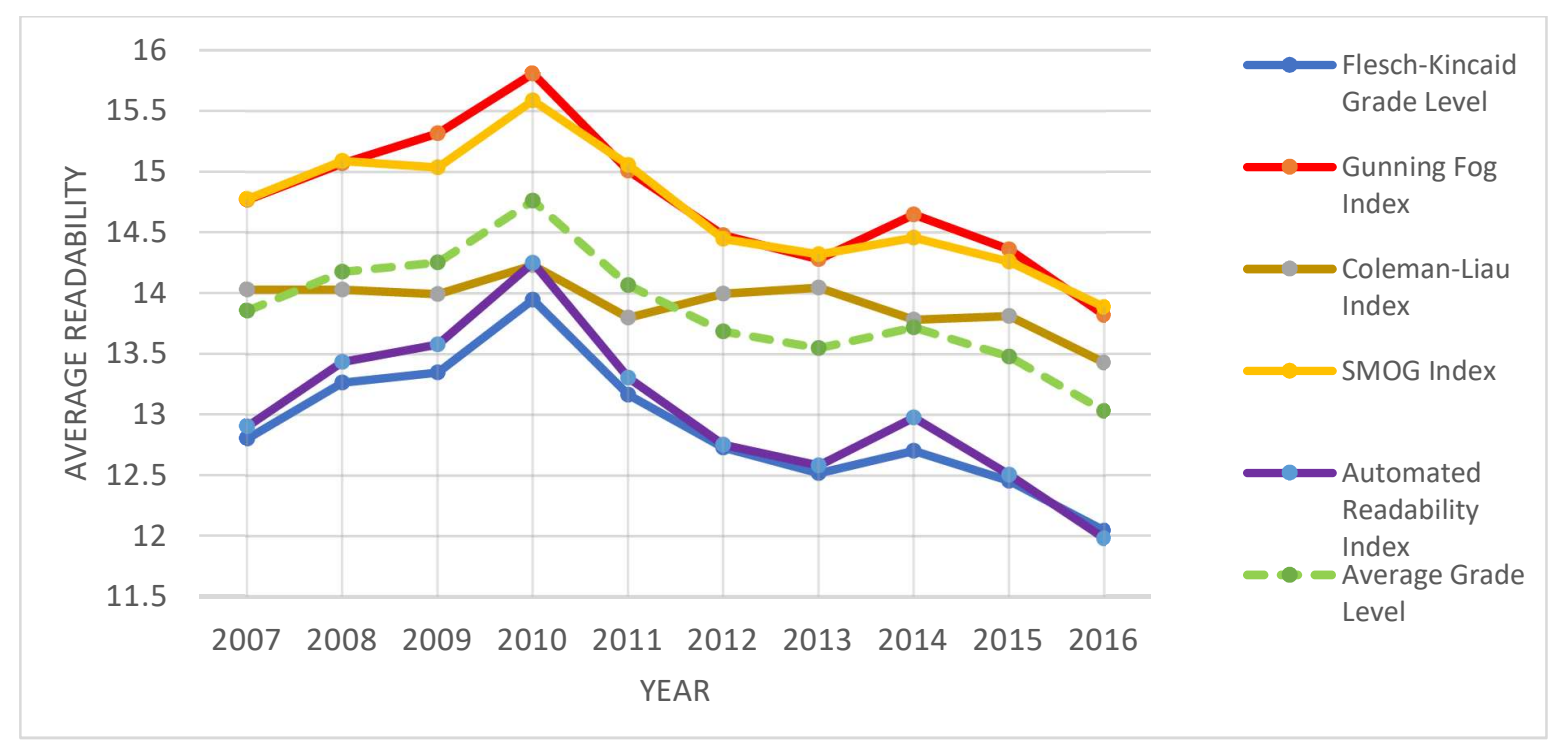

Figure 1 Overall readability trend

These findings address the first research question and indicate that there is a need for further improvements in the readability of sustainability information since any communications need to be observable and clear to be able to send appropriate signals and benefit readers (BliegeBird \& Smith, 2005; Connelly, Certo, Ireland, \& Reutzel, 2011). This might also be a sign of obfuscation which could risk the credibility of sustainability reporting (Nazari et al. 2017).

\subsection{Sustainability Reporting Quantity}

The manual scoring process for sustainability reporting quantity resulted in 44 reports with the score of one (low sustainability reporting), 137 reports with the score of two (medium sustainability reporting), and 83 reports with the score of three (high sustainability reporting). Figure 2 indicates an increase in the length of sustainability reporting during the research period. 
The number of companies with low sustainability reporting decreased while the number of companies publishing medium and high sustainability reporting increased, respectively, by 110 per cent and 150 per cent.

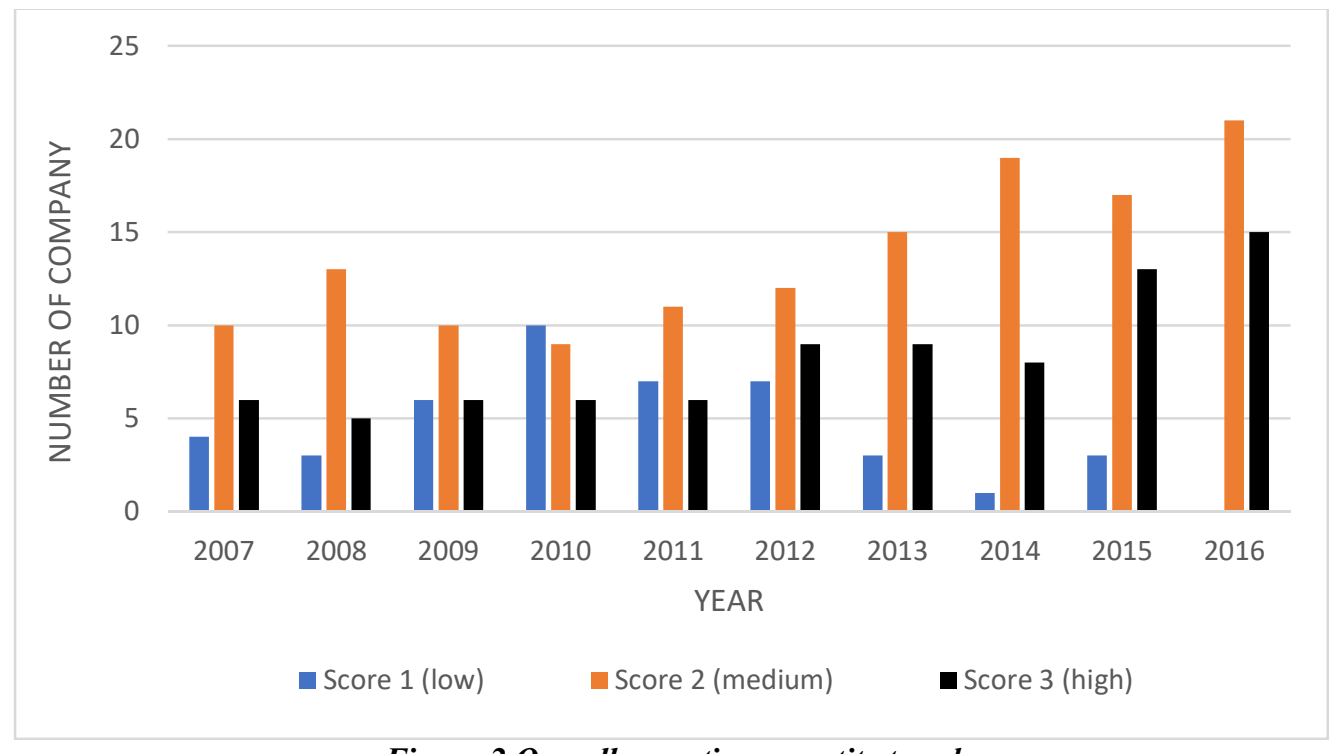

Figure 2 Overall reporting quantity trend

As shown in Figure 3, among the 37 companies that published sustainability information, 16 per cent (6 companies) have consistently been publishing stand-alone reports (high reporting quantity) during the ten-year research period. A medium quantity has been the outcome for 24 per cent ( 9 companies), while no companies have stagnantly been publishing low quantity throughout the research period. Almost one-third of the research sample (30 per cent) have increased their sustainability reporting quantity during the research period, while only two companies ( 5 per cent) followed a downward trend. The quantity of sustainability information published by nine companies (24 per cent) was not stagnant but did not consistently increase or decrease and thus was classified as 'fluctuant'.

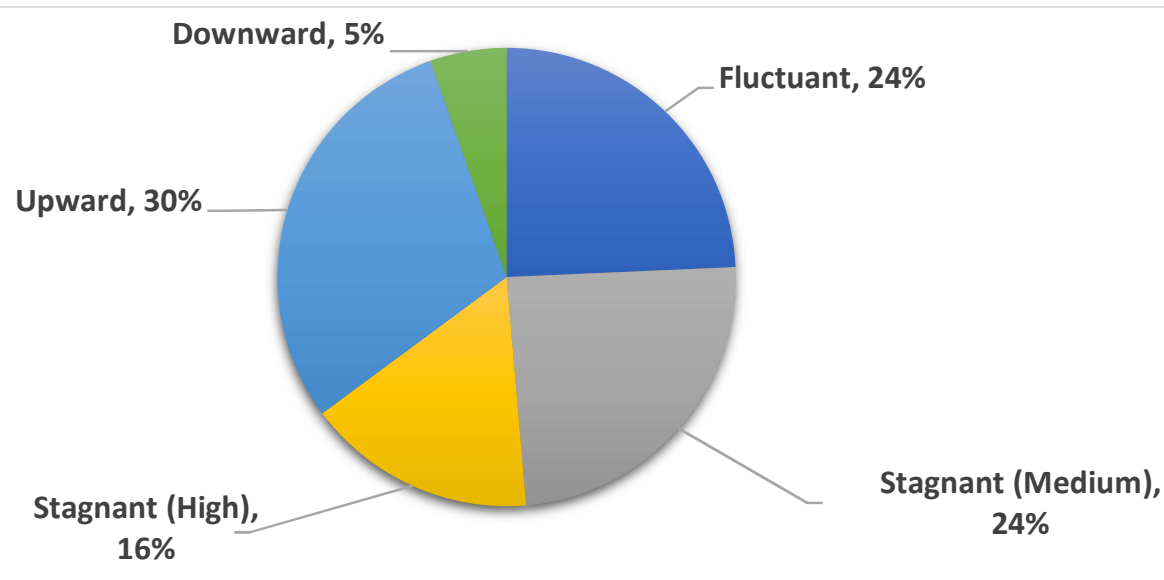

Figure 3 Sample distribution based on the quantity of sustainability reporting 
In general, as shown in Figure 4, a high quantity of sustainability reporting (score 3 ) is associated with lower readability scores than low and medium sustainability reporting quantity (score 1 and 2 respectively). This finding indicates that longer reports published by NZX companies provide more readable information to their users. This result addresses the second research question indicating there is a negative relationship between the quantity and the readability scores of sustainability reporting.

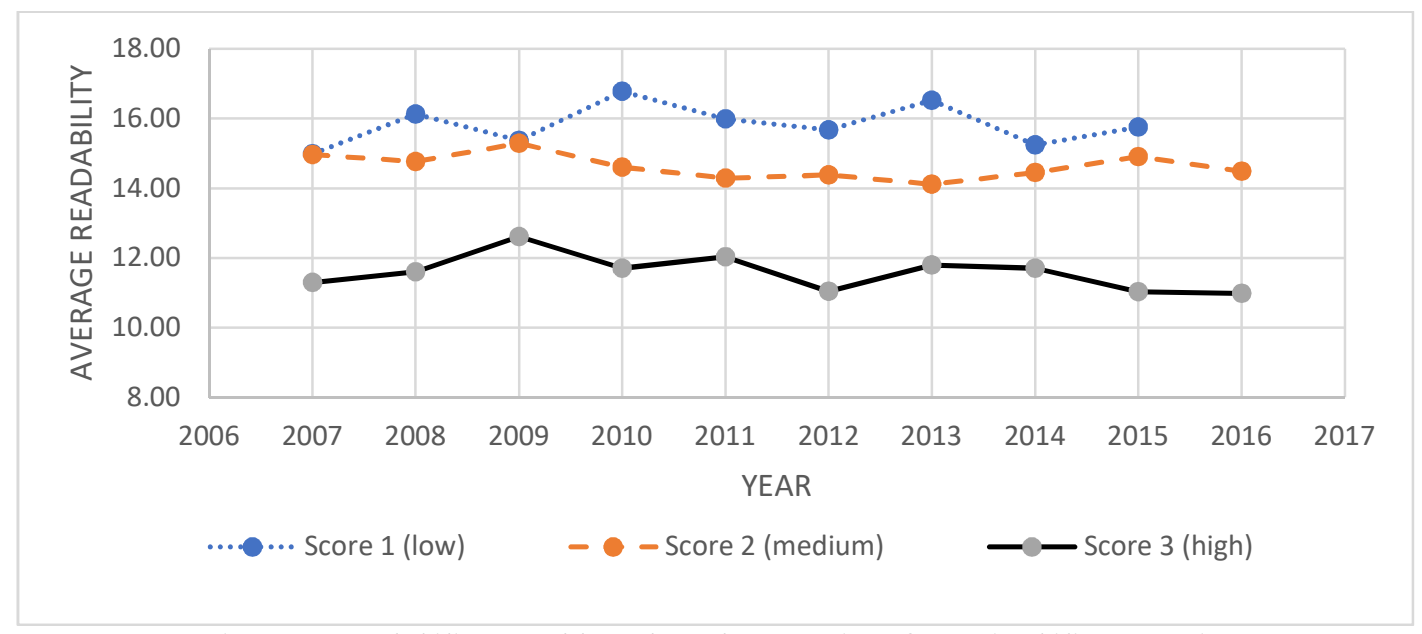

Figure 4 Readability trend based on the quantity of sustainability reporting

Further analysis via a Pearson's Correlation confirmed that there is a statistically significant strong negative correlation between average readability scores and sustainability reporting quantity scores $(r=-0.726, p<0.01)$ highlighting that longer reports are associated with lower readability scores (i.e. they are more readable).

This result is similar to Boritz et al. (2016), which found that longer SOX 404 reports are more readable than shorter SOX 404 reports. However, contrastingly, Geo et al. (2008) found that the length of the report might negatively impair the clarity and readability of the report since longer reports will include too much unnecessary information. Wu \& Pupovac (2019) also believed that lengthy reports are not necessarily providing better quality sustainability information, and they are less useful to users as they are written with high complexity to meet legal requirements. Similarly, Wang et al. (2018) claimed that information overload decreases the readability of narrative information and can act as a way to obfuscate negative sustainability information. However, Loughran and McDonald (2014) recommended that the readability of different types of reports should be examined separately as they are not necessarily comparable. Richards (2011) also found significant differences among the readability scores associated with different types of information published in annual reports.

\subsection{Environmental Sensitivity}

Figure 5 indicates that since 2008, the average readability scores for companies from environmentally sensitive industries have been lower than the scores for companies from nonenvironmentally sensitive industries. The trends shown in Figure 5 address the third research question by illustrating that companies from environmentally sensitive industries presented more readable information than companies from non-environmentally sensitive industries. However, no statistically significant correlation was found between environmental sensitivity and the 
readability score. This signals a possible obfuscation of information to either impress readers or hide poor performance (Nazari et al. 2017).

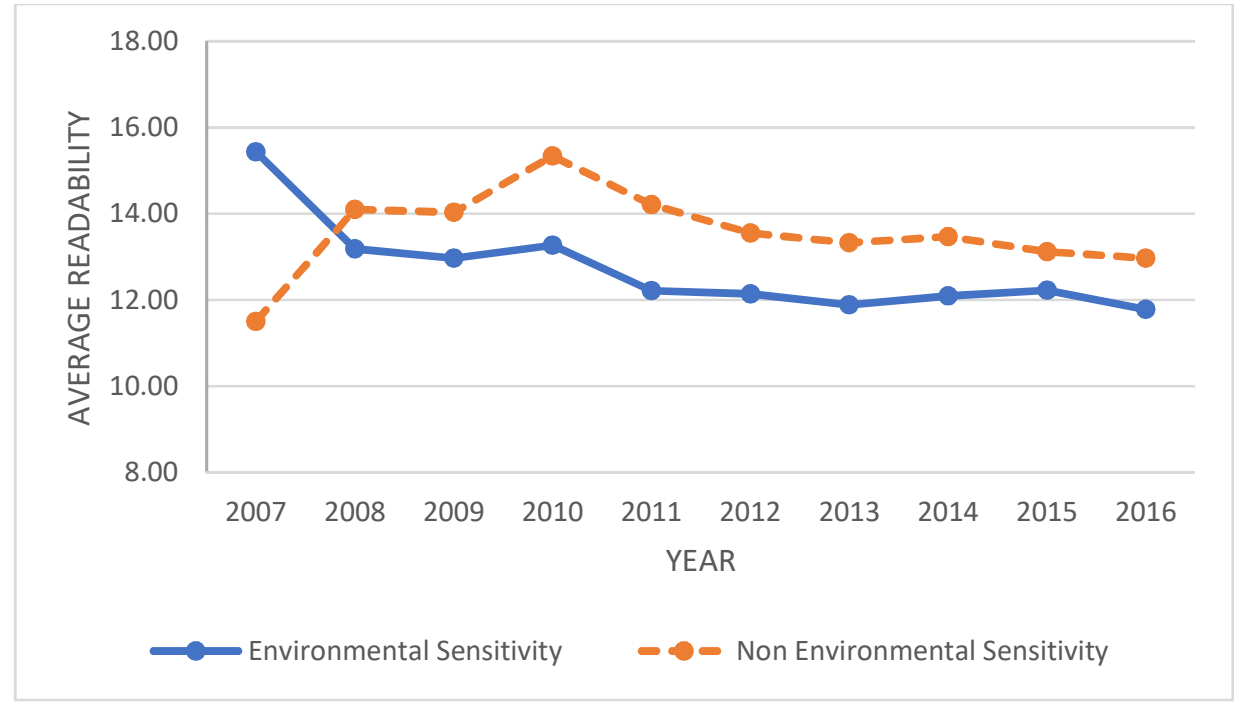

Figure 5 Readability trend based on the environmental sensitivity

Similarly, most prior studies found no relationship between environmental sensitivity and readability; Smeuninx et al. (2016) highlighted that the variations in readability scores could not be explained either by industry differences or environmental and social sensitivity. Richards (2011) tested the readability of corporate communications from listed companies in Australia and New Zealand and found no relationship between readability and a company's operating industry.

\subsection{Global Listing}

Figure 6 addresses the fourth research question by showing no specific relationship between the readability of companies listed in multiple markets and companies listed only on the NZX; suggesting the level of regulations facing companies does not affect the readability of sustainability reporting. This finding is also supported by the result of Pearson's Correlation test. However, Richards (2011) - given they focused on the readability of different sections in annual reports suggested that more regulated information such as an annual report's financial notes is less readable than unregulated sections such as opening letters and CSR reports. Boritz et al. (2016) also found that industries subject to higher levels of regulations publish less readable SOX 404 reports than other industries. 
Nilipour, De Silva \& Li | The Readability of Sustainability Reporting in New Zealand over time

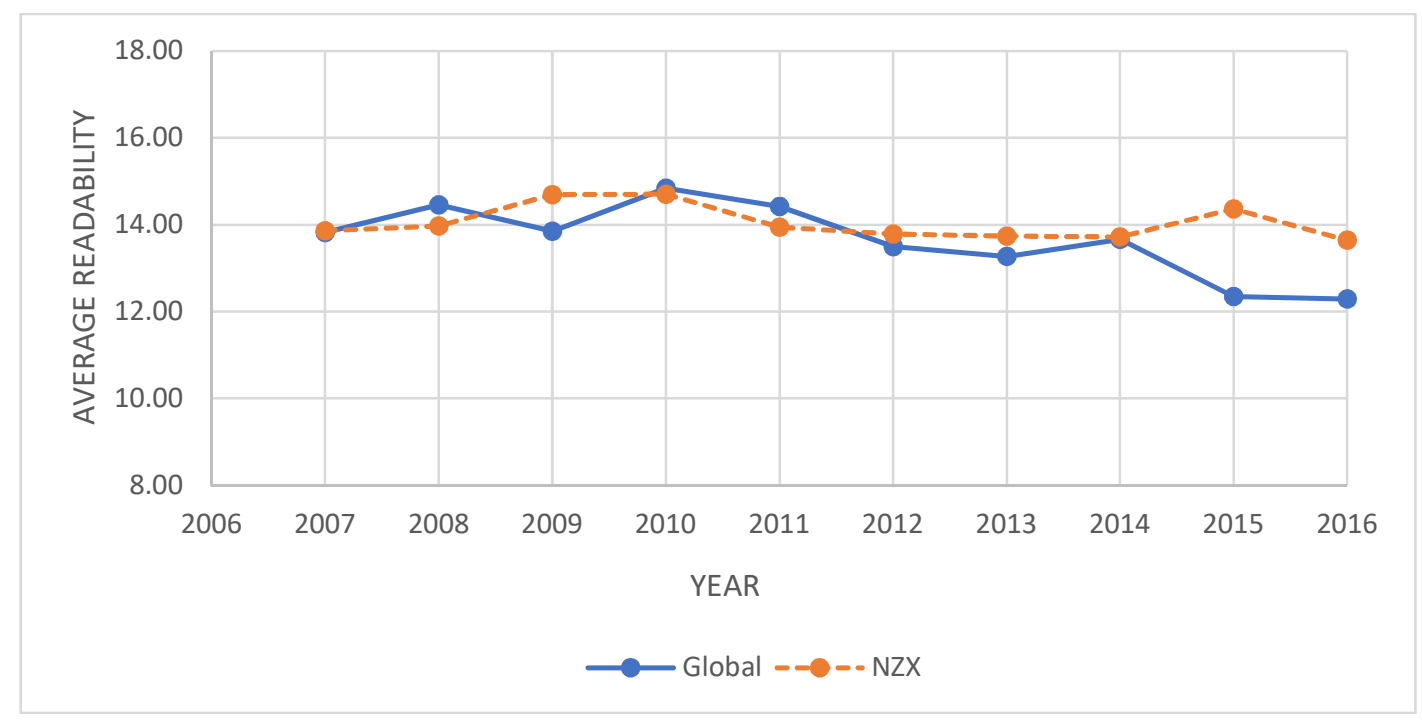

Figure 6 Readability trend based on domestic and global listing

\section{CONCLUSIONS, LIMITATIONS AND FUTURE RESEARCH}

This research examined the readability of sustainability information over time in the annual reports and stand-alone reports of companies listed on the NZX to identify whether stakeholders should be concerned with obfuscation and its impact on their decision-making. In doing so, this research also investigated the relationship between the readability of sustainability reporting and the reporting quantity, environmental sensitivity, and global listing.

The research finds that although the number of companies disclosing sustainability information has increased substantially, and companies have published sustainability reporting of greater length since 2007 - suggesting an increase in the demand for sustainability reporting - no significant improvement was seen in the readability of sustainability reporting. The published sustainability information is classified as 'difficult' to read and might be obfuscating negative sustainability performance. Therefore, improvements are needed if sustainability reporting is to be of greater benefit to stakeholders in their decision-making.

The research finds evidence of a significant statistical relationship between the quantity of sustainability reporting and the readability of such information; high quantity sustainability reporting (stand-alone reports) provides more readable information than low and medium quantity sustainability reporting. Based on signalling theory, more readable sustainability reporting could send a positive signal indicating higher underlying quality (Varda, 2014) and suggests more genuine reporting with less obfuscation (Wang et al., 2018). Thus, the findings suggest that companies with better sustainability performance try to signal the superiority of their performance by publishing more readable sustainability reporting through stand-alone reports or longer annual reports.

The research findings also indicate that companies from environmentally sensitive industries provide more readable sustainability reporting than companies from non-environmentally sensitive industries. This might be the result of a greater incentive for companies operating in environmentally sensitive industries to project a positive social image (Patten, 1991). Despite the expectation for companies listed in multiple markets to have more readable information than 
companies listed only on the NZX, the results find that the readability of sustainability reporting is not influenced by global listing.

This research contributes to the knowledge gap by focusing particularly on the readability of sustainability reporting over time in New Zealand. This is a critical time for New Zealand companies to improve their sustainability reporting due to higher demand from stakeholders (Sustainable Business Council, 2019), and the regulatory changes to the NZX Corporate Governance Code (NZX, 2017). Moreover, this research provides information on the readability of sustainability reporting by applying five common readability indices. The findings encourage companies to increase transparency and clarity of their sustainability reporting by providing stakeholders with more readable information as readability has a differential effect on investors (sophisticated versus unsophisticated) (Miller, 2010). This research further encourages listed companies to consider using readability indices - before publishing their sustainability information - to assess the readability and improve it.

This research, as with any study, has its own limitations. First, the focus was on the small number of companies listed on the NZX. Although the findings might not be applicable to larger stock markets, they are still relevant to markets with similar characteristics. Second, the sustainability reporting was extracted from annual reports and stand-alone reports and scored manually, which could create a level of subjectivity. The impact of this subjectivity was minimised through using pages and part pages to classify sustainability reporting quantity. Third, although this research computed all the common readability indices, it should be noted that these indices are considered only as estimating tools. Finally, annual reports and stand-alone reports are only some of the channels used for disclosing sustainability information. Thus, future research could examine the readability of other communication channels such as sustainability information published on company websites and in social media. A comparison of the readability of sustainability reporting with other information in the management discussion and analysis (e.g. the CEO report) could also be considered. Expanding the analysis to include other company characteristics (e.g. profitability, or size) to see how they affect readability would also be another avenue for future studies to explore.

\section{REFERENCES}

Abu Bakar, A. S., \& Ameer, R. (2011). Readability of corporate social responsibility communication in Malaysia. Corporate Social Responsibility and Environmental Management, 18(1), 50 -60. doi: https://doi.org/10.1002/csr.240

Adams, C. A., \& Harte, G. (1998). The changing portrayal of the employment of women in British banks' and retail companies' corporate annual reports. Accounting, Organisations and Society, 23(8), 781-812. doi: https://doi.org/10.1016/S0361-3682(98)00028-2

Alexander, D., \& Jermakowicz, E. (2006). A true and fair view of the principles/rules debate. Abacus, 42(2), 132-164. doi: https://doi.org/10.1111/j.1467-6281.2006.00195.x

Ballou, B., Heitger, D. L., \& Landes, C. E. (2006). The future of corporate sustainability reporting. Journal of Accountancy, 202(6), 65-74. 
Nilipour, De Silva \& Li | The Readability of Sustainability Reporting in New Zealand over time

Bebbington, J., Larrinaga, C., \& Moneva, J. M. (2008). Corporate social reporting and reputation risk management. Accounting, Auditing \& Accountability Journal, 21(3), 337-361. doi: https://doi.org/10.1108/09513570810863932

Beets, S. D., \& Souther, C. C. (1999). Corporate environmental reports: The need for standards and an environmental assurance service. Accounting Horizons, 13(2), 129-145. doi: https://doi.org/10.2308/acch.1999.13.2.129

BliegeBird, R., \& Smith, E. A. (2005). Signalling theory, strategic interaction, and symbolic capital. Current Anthropology, 46(2), 221-248. doi: https://doi.org/10.1086/427115

Boiral, O. (2013). Sustainability reports as simulacra? A counter-account of A and A+ GRI reports. Accounting, Auditing \& Accountability Journal, 26, 1036-1071. doi: https://doi.org/10.1108/AAAJ-04-2012-00998

Boritz, J.E., Hayes, L., \& Timoshenko, L.M., (2016). Determinants of readability of SOX 404 reports. Journal of Emerging Technologies in Accounting, 13 (2), 145-168. doi: https://doi.org/10.2308/jeta-51593

Brennan, A. (1993). Making room for the environment in annual reports [Abstract]. The Accountants' Journal, 72(7), 61-62.

Brink, P.T., Haines, R., Owen, S., Smith, D., \& Whitaker, B. (1997). Consulting the stakeholder: A new approach to environmental reporting for IBM (U.K.) Ltd. In G Ledgerwood (Ed.), Greening the boardroom: Corporate governance and business sustainability (pp. 175-187). Sheffield, UK: Greenfield Publishing. doi: https://doi.org/10.4324/9781351283489-12

Brockett, A. M., \& Rezaee, Z. (2012). Corporate sustainability. Hoboken, NJ: John Wiley \& Sons. doi: https://doi.org/10.1002/9781119202899

Browne, J. (2002). B.P.'s Browne: Transparency key to restoring trust. Oil \& Gas Journal, $100(44), 34$.

Buzby, S. L. (1974). The nature of adequate disclosure. Journal of Accountancy, 137(4), 38-47.

Christensen, J., \& Demski, J. S. (2004). Asymmetric monitoring: Good versus bad news verification. Schmalenbach Business Review, 56(3), 206-222. doi: https://doi.org/10.1007/BF03396693

Connelly, B. L., Certo, S. T., Ireland, R. D., \& Reutzel, C. R. (2011). Signalling theory: A review and assessment. Journal of Management, 37(1), 39-67. doi: https://doi.org/10.1177/0149206310388419

Cormier, D., \& Gordon, I. M. (2001). An examination of social and environmental reporting strategies. Accounting, Auditing \& Accountability Journal, 14(5), 587-616. doi: https://doi.org/10.1108/EUM0000000006264 
Cormier, D., Gordon, I. M., \& Magnan, M. (2004). Corporate environmental disclosure: Contrasting management's perceptions with reality. Journal of Business Ethics, 49(2), 143 165. doi: https://doi.org/10.1023/B:BUSI.0000015844.86206.b9

Courtis, J. K. (1998). Annual report readability variability: Tests of the obfuscation hypothesis. Accounting, Auditing \& Accountability Journal, 11(4), 459-472. doi: https://doi.org/10.1108/09513579810231457

Deegan, C. (2002). Introduction: The legitimising effect of social and environmental disclosures a theoretical foundation. Accounting, Auditing \& Accountability Journal, 15(3), 282-311. doi: https://doi.org/10.1108/09513570210435852

DuBay, W. (2004). The principles of readability. Costa Mesa: Impact Information. doi:10.1.1.91.4042

Freedman, M., \& Stagliano, A. J. (1992). European unification, accounting harmonisation, and social disclosures. The International Journal of Accounting, 27(2), 112-122.

Frias-Aceituno, J. V, Rodriguez-Ariza, L., \& Garcia-Sanchez, I. M. (2012). Explanatory factors of integrated sustainability and financial reporting. Business Strategy and the Environment, 23(1), 56-72. doi: https://doi.org/10.1002/bse.1765

Godfrey, J., Hodgson, A., \& Holmes, S. (2000). Accounting theory. Milton, Queensland, Australia: John Wiley \& Sons.

Gray, R. (1990). Social and environmental accounting in the Western capitalist economies: A review (Working Paper Series No. 7). Christchurch, New Zealand: University of Canterbury, Faculty of Commerce, Department of Accountancy.

Gray, R., Kouhy, R., \& Lavers, S. (1995). Corporate social and environmental reporting: A review of the literature and a longitudinal study of U.K. disclosure. Accounting, Auditing \& Accountability Journal, 8(2), 47-77. doi: https://doi.org/10.1108/09513579510146996

Gray, R., Owen, D., \& Adams, C. (1996). Accounting and accountability: Changes and challenges in corporate social and environmental reporting. London, UK: Prentice Hall.

Gunning, R. (1952). The technique of clear writing. New York, NY: McGraw-Hill.

Guo, P., Zhong, C., Chen, Y., Wang, X., Li, W. (2008). A journey to discover values: Study of sustainability reporting in china. Available URL: http://www.syntao.com/Uploads/\%7B065554F3-B9D7-4DDC-8BA9

3DFE894119A9\%7D_A\%20journey\%20to\%20discover\%20values\%202008.pdf. Accessd 20 November 2017.

Guthrie, J., \& Parker, L. D. (1990). Corporate social disclosure practice: A comparative international analysis. Advances in Public Interest Accounting, 3, 159-175. 
Nilipour, De Silva \& Li | The Readability of Sustainability Reporting in New Zealand over time

Habbitts S, Gilbert S. 2007. Reporting the business implications of climate change in sustainability reports. Retrieved from https://www.globalreporting.org/ resourcelibrary/Reporting-on-theBusiness-Implications-of-Climate-Change-in-Sustainability-Reports.pdf [16 June 2017]

Hackston, D., \& Milne, M. J. (1996). Some determinants of social and environmental disclosures in New Zealand companies. Accounting, Auditing \& Accountability Journal, 9(1), 77-108. doi: https://doi.org/10.1108/09513579610109987

Hammond, K., \& Miles, S. (2004). Assessing quality assessment of corporate social reporting: U.K. perspectives. Accounting Forum, 28(1), 61—79. doi:10.1016/j.accfor.2004.04.005

Harris T.L., \& Hodges, R.E. (1995). The literacy dictionary, The vocabulary of reading and writing. Newark, DE, USA: International Reading Assn.

Hooghiemstra, R. (2000). Corporate communication and impression management: New perspectives why companies engage in corporate social reporting. Journal of Business Ethics, 27(1-2), 55-68. doi: https://doi.org/10.1023/A:1006400707757

Hooks, J., Coy, D., \& Davey, H. (2002). The information gap in annual reports. Accounting, Auditing \& Accountability Journal, 15(4), 501-522. doi: https://doi.org/10.1108/09513570210440577

Huang, C.-L., \& Kung, F.-H. (2010). Drivers of environmental disclosure and stakeholder expectation: Evidence from Taiwan. Journal of Business Ethics, 96, 435-451. doi: https://oi.org/10.1007/s10551-010-0476-3

Imhoff, E. A. Jr. (1992). The relation between perceived accounting quality and economic characteristics of the firm. Journal of Accounting and Public Policy, 11(2), 97-118. doi: https://doi.org/10.1016/0278-4254(92)90019-T

Kincaid, J. P., Fishburne Jr, R. P., Rogers, R. L., \& Chissom, B. S. (1975). Derivation of new readability formulas (automated readability index, fog count and Flesch reading ease formula) for Navy enlisted personnel: Naval Technical Training Command Millington TN Research Branch. doi: https://doi.org/10.21236/ADA006655

Klare, G. R. (1963). The measurement of readability. Ames: Iowa State University Press.

KPMG. (2017). The road ahead: The KPMG survey of corporate responsibility reporting 2017. Retrieved from https://home.kpmg.com/content/dam/kpmg/campaigns/csr/pdf/CSR_Reporting_2017.pdf

Kumar, G. (2014). Determinants of readability of financial reports of U.S.-listed Asian companies. Asian Journal of Finance \& Accounting, 6(2). doi: https://doi.org/10.5296/ajfa.v6i2.5695

Larrinaga-González, C., Carrasco-Fenech, F., Caro-González, F. J., Correa-Ruiz, C., \& PáezSandubete, J. M. (2001). The role of environmental accounting in organizational change. Accounting, Auditing \& Accountability Journal, 14(2), 213-239. doi: https://doi.org/10.1108/09513570110389323 
Legendre, S., \& Coderre, F. (2013). Determinants of GRI G3 application levels: the case of the fortune global 500. Corporate Social Responsibility and Environmental Management, 20(3), 182-192. doi: https://doi.org/10.1002/csr.1285

Lehavy, R., Li, F., \& Merkley, K. (2011). The effect of annual report readability on analyst following and the properties of their earnings forecasts. Accounting Review, 86, 1087-1115. doi: https://doi.org/10.2308/accr.00000043

Li, F. (2008). Annual report readability, current earnings, and earnings persistence. Journal of Accounting and Economics, 45, 221-247. doi: https://doi.org/10.1016/j.jacceco.2008.02.003

Lo, K., Ramos, F., \& Rogo, R. (2017). Earnings management and annual report readability. Journal of Accounting and Economics, 63(1), 1-25. doi: https://doi.org/10.1016/j.jacceco.2016.09.002

Loughran, T., \& McDonald, B. (2014). Measuring readability in financial disclosures. Journal of Finance, 69(4), 1643-1671. doi: https://doi.org/10.1111/jofi.12162

McCrary, D. (2002). Green accounting. California CPA, 71(3), 12-16.

McLaughlin, G. H. (1969). SMOG grading: A new readability formula. Journal of Reading, 12, $639-646$.

Melo T., \& Garrido-Morgado A. (2012). Corporate reputation: a combination of social responsibility and industry. Corporate Social Responsibility and Environmental Management, 19(1), 11-31. doi: https://doi.org/10.1002/csr.260

Merkl-Davies, D.M., \& Brennan, N.M., (2007). Discretionary disclosure strategies incorporate narratives: incremental information or impression management? Journal of Accounting Literature, 27, 116-196.

Mermod A.Y., \& Idowu S.O. (2013). Corporate Social Responsibility in the Global Business World. Springer: Berlin Heidelberg, Germany.

Miller, B.P. (2010). The effects of reporting complexity on small and large investor trading. The Accounting Review, 85(6), 2107-2143. doi: https://doi.org/10.2308/accr.00000001

Milne, M. J., \& Adler, R. W. (1999). Exploring the reliability of social and environmental disclosures content analysis. Accounting, Auditing \& Accountability Journal, 12(2), 237256. doi: https://doi.org/10.1108/09513579910270138

Morunga, M. and Bradbury, M. E. (2012) The impact of IFRS on annual report length, Australasian Accounting, Business and Finance Journal, 6(5), 47-62.

Nazari, J.A., Hrazdil, K., \& Mahmoudian, F. (2017). Assessing social and environmental performance through narrative complexity in CSR reports. Journal of Contemporary Accounting \& Economics, 13, 166-178. doi: https://doi.org/10.1016/j.jcae.2017.05.002 
Nilipour, De Silva \& Li | The Readability of Sustainability Reporting in New Zealand over time

New Zealand Exchange. (2017). NZX Corporate Governance Code. Available URL: https://www.nzx.com/files/attachments/257864.pdf

Newson, M., \& Deegan, C. (2002). Global expectations and their association with corporate social disclosure practices in Australia, Singapore, and South Korea. The International Journal of Accounting, 37, 183-213. doi: https://doi.org/10.1016/S0020-7063(02)00151-6

O'Dwyer, B. (2002). Managerial perceptions of corporate social disclosure: An Irish story. Accounting, Auditing \& Accountability Journal, 15(3), 406-436. doi: https://doi.org/10.1108/09513570210435898

Owen, D. (2006). Emerging issues in sustainability reporting [Editorial]. Business Strategy and the Environment, 15, 217-218. doi: https://doi.org/10.1002/bse.530

Parsons, R., \& McKenna, B. J. (2005, November). Constructing social responsibility in mining company reports. In T. Lê \& M. Short (Eds.), Proceedings of the International Conference on Critical Discourse Analysis Theory into Research (pp. 595-608). Available URL: http://195.130.87.21:8080/dspace/bitstream/123456789/262/1/Parsons\&McKennaconstructi ngsocialresponsibility.pdf

Patten, D. M. (1991). Exposure, legitimacy, and social disclosure. Journal of Accounting and Public Policy, 10(4), 297-308. doi: https://doi.org/10.1016/0278-4254(91)90003-3

Perks, R. W. (1993). Accounting and society. London, UK: Chapman \& Hall.

Riahi-Belkaoui, A. (2004). Accounting theory. London, UK: Thomson Learning.

Richards, G. (2011). Readability and thematic manipulation in corporate communications: A multi-disclosure and Trans-Tasman investigation. University of Canterbury, Christchurch, New Zealand.

Roberts, R. W. (1992). Determinants of corporate social responsibility disclosure: An application of stakeholder theory. Accounting, Organisations and Society, 17(6), 595-612. doi: https://doi.org/10.1016/0361-3682(92)90015-K

Rowe, A. (2013). Sustainability accounting and reporting. Sustainability in Australian business (pp. 219-248). Milton, Australia: John Wiley \& Sons Australia.

Rutherford, B.A. (2003). Obfuscation, textual complexity and the role of regulated narrative accounting disclosure in corporate governance. Journal of Management and Governance, 7 , 187-210. doi: https://doi.org/10.1023/A:1023647615279

Schroeder, N., \& Gibson, C. (1990). Readability of management's discussion and analysis. Accounting Horizons, 4(4), $78-87$.

Scott, P. (2001). Reporting all over the world. Environmental Finance, December-January, 3637. Available URL: http://www.nextstep.co.uk/uploadedfiles/pdf/article5.pdf 
Singhvi, S. S., \& Desai, H. B. (1971). An empirical analysis of the quality of corporate financial disclosure. The Accounting Review, 46(1), 129-138.

Skinner, D. J. (1994). Why firms voluntarily disclose bad news. Journal of Accounting Research, 32(1), 38 -60. doi: https://doi.org/10.2307/2491386

Smeuninx, N., De Clerck, B., \& Aerts, W. (2016). Measuring the readability of sustainability reports: A corpus-based analysis through standard formulae and NLP. International Journal of Business Communication, 1-34. doi: https://doi.org/10.1177/2329488416675456

Smith, M., \& Taffler, R. (1992). The chairman's statement and corporate financial performance. Accounting \& Finance, 32(2), 75-90. doi: https://doi.org/10.1111/j.1467629X.1992.tb00187.x

Solomon, A., \& Lewis, L. (2002). Incentives and disincentives for corporate environmental disclosure. Business Strategy and the Environment, 11(3), 154-169. doi: https://doi.org/10.1002/bse. 328

Statistics New Zealand. (2013). Education and training in New Zealand. Retrieved from https://www.stats.govt.nz/infographics/education-and-training-in-new-zealand

Statistics New Zealand. (2018). 2018 Census totals by topic - national highlights. Retrieved from https://www.stats.govt.nz/information-releases/2018-census-totals-by-topic-nationalhighlights

Suchman, M. C. (1995). Managing legitimacy: Strategic and institutional approaches. The Academy of Management Review, 20(3), 571-610. doi: https://doi.org/10.5465/amr.1995.9508080331

Sustainable Business Council. (2019). In Good Company: How New Zealanders assess the sustainability of brands. Available URL: https://www.sbc.org.nz/ data/assets/pdf file/0004/183208/SBC_PorterNovelli_Perceptive In-good-company Report_November-2019-for-web.pdf

Toms, J. S. (2002). Firm resources, quality signals and the determinants of corporate environmental reputation: Some U.K. evidence. The British Accounting Review, 34(3), 257282. doi: https://doi.org/10.1006/bare.2002.0211

Tregidga, H., \& Milne, M. (2006). From sustainable management to sustainable development: A longitudinal analysis of a leading New Zealand environmental reporter. Business Strategy and the Environment, 15(4), 219-241. doi: https://doi.org/10.1002/bse.534

Unerman, J. (2000). Methodological issues: Reflections on quantification in corporate social reporting content analysis. Accounting, Auditing \& Accountability Journal, 13(5), 667-681. doi: https://doi.org/10.1108/09513570010353756 
Nilipour, De Silva \& Li | The Readability of Sustainability Reporting in New Zealand over time

Varda, H. (2014). Signalling sustainability: Drivers, types of signals and methods a comparative study between certified and non-certified companies within the U.K. sustainable fashion sector (Unpublished doctoral dissertation). Cardiff University, Cardiff, Wales.

Wang Z., Hsieh T-S., \& and Sarkis J. (2018). CSR performance and the readability of CSR reports: too good to be true? Corporate Social Responsibility and Environmental Management, 25, 66-79. doi: https://doi.org/10.1002/csr.1440

Wiseman, J. (1982). An evaluation of environmental disclosures made in corporate annual reports. Accounting, Organisations and Society, 7(1), 53-63. doi: https://doi.org/10.1016/0361$\underline{3682(82) 90025-3}$

Wu, D. \& Pupovac, S. (2019). Information overload in CSR reports in China: An exploratory study. Australasian Accounting, Business and Finance Journal, 13(3), 3-28. doi: https://doi.org/10.14453/aabfj.v13i3.2

Yongvanich, K., \& Guthrie, J. (2006). An extended performance reporting framework for social and environmental accounting. Business Strategy and the Environment, 15(5), 309-321. doi: https://doi.org/10.1002/bse.541 